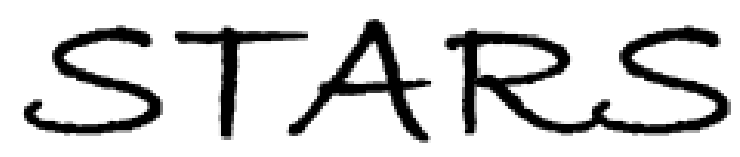

Rhetoric of Health \& Medicine

Volume 3

Issue 2 Mental Health Rhetoric

Article 1

2020

\title{
Teaching and Researching with a Mental Health Diagnosis: Practices and Perspectives on Academic Ableism
}

Ann Green

agreen@sju.edu

Alyssa _

alyhillary@gmail.com

Lucia Dura

Idura@utep.edu

Patrick Harris

patrickharris@unr.edu

Leah Heilig

Leah.Heilig@ttu.edu

See next page for additional authors

Part of the Health Communication Commons, Medical Humanities Commons, and the Psychiatric and Mental Health Commons

Find similar works at: https://stars.library.ucf.edu/rhm

University of Central Florida Libraries http://library.ucf.edu

\section{Recommended Citation}

Green, Ann; _, Alyssa; Dura, Lucia; Harris, Patrick; Heilig, Leah; Kirby, Bailey; McClintick, Jay; Pfender, Emily; and Carrasco, Rebecca (2020) "Teaching and Researching with a Mental Health Diagnosis: Practices and Perspectives on Academic Ableism," Rhetoric of Health \& Medicine: Vol. 3 : Iss. 2 , Article 1.

Available at: https://stars.library.ucf.edu/rhm/vol3/iss2/1

This Article is brought to you for free and open access by STARS. It has been accepted for inclusion in Rhetoric of Health \& Medicine by an authorized editor of STARS. For more information, please contact lee.dotson@ucf.edu.

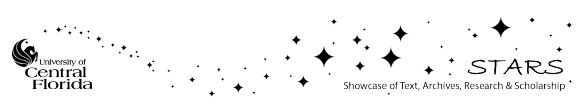




\section{Teaching and Researching with a Mental Health Diagnosis: Practices and Perspectives on Academic Ableism}

\section{Cover Page Footnote}

Acknowledgements: Thank you to the editors of RHM for their guidance and patience as this article evolved, and thanks to the insightful comments from the anonymous reviewers whose constructive and supportive suggestions shaped the final version. Particular thanks to reviewer \#2 for identifying the bell hook quote used from Talking Back (1989). In addition, thanks to Susan Naomi Bernstein who provided particular editorial assistance during the final editing stage.

\section{Authors}

Ann Green, Alyssa _, Lucia Dura, Patrick Harris, Leah Heilig, Bailey Kirby, Jay McClintick, Emily Pfender, and Rebecca Carrasco 


\title{
Teaching and Researching with a Mental Health Diagnosis: Practices and Perspectives on Academic Ableism
}

Ann E. Green, Alyssa, Rebecca Carrasco, Lucía Durá, Patrick Harris, Leah Heilig, Bailey Kirby, Jay McClintick, and Emily Pfender

\begin{abstract}
Nine people with mental health diagnoses wrote a dialogue to discuss how we navigate our conditions and ask for accommodations within an academic setting. We cogitate on the challenges of obtaining a diagnosis, how and when we disclose, the affordances and challenges of our symptoms, seeking accommodations, and advocating for ourselves. We consider how current scholarship and other perspectives are changing the conversation about mental health in the academy. We conclude that while the 2008 revisions to the Americans with Disabilities Act have addressed necessary accommodations, that those with mental health conditions are still seeking access.
\end{abstract}

Key words: Mental health, accommodations, ableism, mental health disability 1

Margaret Price (2011) argues that "Academic discourse operates not just to omit, but to abhor mental disability — to reject it, to stifle it and expel it” (p. 8). We used the form of a dialogue as the many voices represented here created a space for play. Because a dialogue includes multiple voices it creates space for gaps, silences, and disconnections which can create a

\footnotetext{
1 The "l" in the opening paragraphs of each section are Ann's.
} 
generative space for disagreements and new thinking. This dialogue uses the multivocal affordances of a non-traditional academic genre as a way to push back against silence and stigma surrounding mental health in academe. Rather than exploring mental disabilities as one voice with one argument or trying to fit our words into a neat framework, the dialogue itself reveals some of the messiness of our process of seeking rhetoricity (Price, 2011; Lewiecki-Wilson, 2003). Specifically, we have come together to explore teaching and researching with mental health diagnoses. Recognizing diagnosis as a process, this dialogue takes up such issues as getting an accurate diagnosis; deciding when, how, and if to disclose a mental health diagnosis; recognizing the challenges of researching and teaching with mental health-related symptoms; and knowing how to ask for accommodations, including knowing what accommodations to ask for. If "ableism contributes to the construction of a rigid, elitist, hierarchical and inhumane academic system," then writing to create a community — in a limited way — is a radical act (Price, 2011, p. 8).

Our dialogue brings together diverse RHM scholar-teachers who've been diagnosed (or misdiagnosed) with such conditions as autism, bipolar disorder, borderline personality disorder (BPD), depression and anxiety, obsessive compulsive disorder (OCD), and post-traumatic stress disorder (PTSD). Importantly, this dialogue brings a diversity of voices together to exchange ideas and insights on this important topic: Many of us have multiple diagnoses and/or chronic health conditions. We are white and Latinx. We are cisgendered, genderqueer, non-binary, and trans. We are asexual, straight, bisexual, and gay. We are graduate students, full-time staff, tenure-track/tenured faculty, and non-tenure track faculty in neuroscience, computational science, and English. We come from different fields and have different kinds of training. We are 
much more than any of these labels indicate, of course. Through blending our voices and parsing our conversation, we hope to contribute generative new insight into this topic.

\section{Method}

Thus, this dialogue is edited from a long Google document composed over about a couple of months in January, February, and March 2019. The dialogue took place in two parts: a community building piece (referred to as the cocktail part of the dialogue) and a second piece more directly related to teaching and researching with a mental health diagnosis. Drawing particularly from hooks' (1994) call to create community and value each individual voice and Ellsworth's (1989) assertion that critical pedagogy must account for the subject positions of the participants, the first part of the dialogue included a series of questions that asked participants to reveal their location in the world, both personally and professionally (see Appendix A). Most of the writing we did here does not appear in the final version, but it was helpful for setting the stage for the dialogue that followed.

After this icebreaker of sorts, participants responded to a series of questions about teaching and researching with a mental health diagnosis in a dialogue form (see Appendix A). We did set up a few times for synchronous collaboration, but most of the collaboration via Google documents was asynchronous with folks coming in and out of the dialogue as their schedules (and time zones) allowed.

Beginning by situating ourselves with disclosures about our academic and personal lives and a bit about what we hope, dream, and experience would, I hoped, create a space that would be more "safe" than diving straight into the connections between mental health diagnoses and 
our scholarship. ${ }^{2}$ A second hope was that the participants in the dialogue might form the kinds of informal networks that I have found so useful in my own career. Informal networks beyond my institution or even my discipline have proved useful for letters for jobs or promotions, for future collaborations for conference presentations and articles, and for the sharing of articles and research. ${ }^{3}$ I hoped this dialogue might lead to similar connections.

I hoped that creating space and time for community-building for the participants would enable us to engage more fruitfully in our discussion of the complexities of teaching and researching with a mental health diagnosis. However, one of the "fails" of this method was that I tend to work intuitively and definitely did not explain this clearly before we began. Now, looking back, I can articulate my method, but in the moment, it was muddled. And not everyone is comfortable with disclosing - even if it will not be published. We began with 12 dialogue participants and ended up with eight. At least one dropped out because she did not choose to participate in the first part of the dialogue where folks disclosed their "politics of location" (Rich, 1994). I am not sure why others left the dialogue. An additional limiting factor was my level of comfort with technology. A future dialogue lead author might be more comfortable with something like video conferencing and transcription that enables more synchronous communication. Finally, while our diagnoses themselves are "social creations discursively

\footnotetext{
2 The word "safety" is in quotes here for two reasons. Because classrooms-even classrooms based in feminist/anti-racist pedagogy--are not inherently safe spaces (Ellsworth, 1989; hooks, 1994) and because minoritized students in majority white/male/cis-gendered spaces may take great risks to be there. ${ }^{3}$ In addition to the introductions provided by the icebreakers, participants shared a picture of themselves. I thought this might be helpful for me as an editor, as when I previously participated in an RHM dialogue (Molloy et al., 2018) I struggled with "picturing" other participants as I read their words. I hoped that by sharing images, I would have an image in mind for Alyssa, Bailey, Emily, Leah, Lucia, Jay, Patrick, and Rebecca that would help me "see" their words in the context of their embodied rhetorics and, when relevant, their tattoos (Prendergast, 2001). What would have been even more helpful, as we wrote the dialogue, would have been an image coming up with the name, so that connection would have been tighter in the editing.
} 
constructed as immutable truths," we are living with them as "illnesses" (see Molloy, 2015

riffing on Kleinman).

\section{Naming}

While at this moment, the field is addressing academic ableism (Dolmage, 2017; Price, 2011; Yergeau, 2017, 2013), such conversations invite disclosure of disability status. For some of us, talking openly about our diagnosis is new and raw; our conversation yielded a number of important areas of consensus and disagreement. Some of us, for instance, use person-centered language (we are people with mental health diagnoses), but some of us are comfortable seeing our mental health diagnosis as a part of our identity or even insist upon doing ${ }^{4}$

We are bipolar, for example, as well as many other things. We see this dialogue as an opening for other dialogues, a place where we are wrestling with ideas and where others can enter the conversation, disagree, argue, and pontificate. We are vulnerable here about what we do not know, whether that is "Mad Pride" ${ }^{5}$ or the accommodations we are entitled to. We disagree, argue, and support one another. Through dialogue, we hope to embrace mental disability, to highlight its affordances, and to acknowledge the ways that it shapes our experiences, our words, and our work. What you have here is our distilled knowledge-making from a conversation that took place over several months and that was originally 80 pages long. We hope the rest of this dialogue invites you into the conversation.

\footnotetext{
${ }^{4}$ C.F. "Schizophrenia as neurodiversity." https://intersectionalneurodiversity.wordpress.com/2017/01/25/schizophrenia-as-neurodiversity/

5 "Mad Pride" is a movement similar to Gay Pride that reclaims and celebrates terms like "mad" and advocates for additional resources for those experiencing symptoms of mental illness. Most active from 1999-2012 in Great Britain, although chapters appeared in seven countries, the movement sought to destigmatize severe mental illnesses like schizophrenia and bipolar disorder via parades, cabarets, protests, and other public events (Abraham, 2016; Glasser, 2008)
} 


\section{Struggling to Find a Diagnosis}

In F. Fred Reynolds (2018) “A Short History of Mental Health Rhetoric Research (MHRR)," he argues that research into mental health rhetoric has shifted from caregivers and medical professionals to "patients and their families" (p. 3). In the most recent clusters of research, Reynolds (2018) cites Margaret Price's (2011) foundational Mad at School: Rhetorics of Mental Disability and Academic Life and articles by Catherine Prendergast (2001), Cynthia Lewiecki-Wilson (2003) as well as more recent research by Drew Holladay (2017) as sources of scholarship that combined research into mental health diagnoses with research into disability studies to develop "mental disability rhetoric" as an area of study. One commonality among recent scholars of mental health diagnoses is their struggle to create space for the voices of those with mental disabilities. ${ }^{6}$ Each shift in methodology has created more space for the words of those with mental health diagnoses, but what happens if we actually go a step beyond Price's (2011) call to "listen to the mad subject" and write as the mad subject (p. 41)? What does it mean to write "mad" and grapple with a DSM-5 assessment of "what you have"? Participants in our dialogue have similar conflicts when struggling to find the correct diagnosis, medication, and treatment. Moreover, some of us view our diagnoses as aspects of our identity while others of us want to separate our diagnoses from our core ideas of self (and all of us, I think, acknowledge the postmodern idea of a discursive, shifting self, constructed of language). Below, readers will find selections from our conversation on the process of gaining diagnostic label(s).

Lucia: It's possible that because I've been successful people think I have my ducks in a row, but I don't. Nobody does! Oddly, my anxiety piqued when I got a positive response for tenure. Who

\footnotetext{
${ }^{6}$ I am using Price's (2011) preferred term, mental disability, interchangeable with mental health diagnoses.
} 
would have imagined that such good news would literally make me sick? Last summer, I struggled with panic attacks and anxiety disguised as depression. These things were always there, but they were detonated over the summer.

Jay: I didn't have any formal diagnosis until graduate school, when my mental health became so bad that my choices were naming my mental illness and intervening on it or walking off the roof of a parking garage. I didn't know I was trans until then. I think this experience of earlier diagnosis probably has more to do with people with the privilege to spot and intervene early for people.

Bailey: Interesting! My greatest challenge and hope is to figure out my brain again. I'm newly diagnosed and medicated for bipolar II (finally!), and the biggest surprise of that process has been the change in how I experience reading and writing. Writing now feels like a brand-new experience.

Patrick: Congrats on getting your official diagnosis; it's a pivotal moment. Don't forget that these medications often take a good six months to really settle in, a window which you're still within.

Bailey: Thanks, Patrick! Today I read something significant for the first time since beginning medication, but. . .it was Derrida—so does that really make it a win??

Leah: I had a similar experience to Jay. My official diagnosis is still new. As an adult, I had difficulty getting correct treatment/diagnosis. General practitioners were quick to dismiss my experiences and requests for referrals in favor of prescribing medications that my insurance didn't always cover. . . To be blunt, it's far more difficult to get a diagnosis than most people realize, particularly with health services being as constricted as they are, and mental illness narratives still easily dismissed. 
Price contrasts "access" with "accommodation" (p. 130). While some of us have had accommodations, or "fixes" for our particular needs, academia is not created for "access," “designing spaces . . . in ways that are flexible, multimodal, and responsive to feedback" (p. 130). Despite educational privilege--if not economic privilege--we have all had struggles to obtain care and resources for our neuroatypicality. Often it is in a moment of crisis, when our previous strategies no longer work, when we get access to diagnosis and treatment. While the ACA included more provisions for mental health care, few of us have found care easy to obtain. In late capitalism in a cultural moment that emphasizes speed, diagnosing and treating mental health disorders require that most precious commodity: time. We do not have "crip time" (Samuels, 2017). Time to find the right diagnosis, the right combination of meds, the time to let our bodies adjust to those medications. In the hyper-productive atmosphere of the neoliberal university, the inability to access care can lead to a failure to "produce." The systemic denial of neurodiversity can lead us to think of our struggles as an individual failing rather than a structural flaw of neoliberal austerity. This dialogue highlights the collective struggles that neuroatypical academics encounter as we try to do our work.

\section{Deciding on Whether or Not to Disclose}

With a diagnosis of depression, nothing could be situational, and all other symptoms were read through that lens. In Quite Mad: An American Pharma Memoir, Sarah Fawn Montgomery (2018) demonstrated that, in the U.S. health care system, it is generally much easier to get a prescription than a diagnosis. ${ }^{7}$ While I have had my own mental health diagnosis for some time, I had not thought about or questioned how I had gotten it or whether or not it was 
valid; what had frustrated me was being unable to recover. Having a diagnosis of depression seemed to make every doctor's visit an argument about changing antidepressants or going back on them. A doctor's visit to request malaria meds for travel resulted in a conversation about restarting Lexapro when I expressed fatigue. Heart palpitations during my prison classes triggered another discussion about restarting antidepressants, although an EKG later in the appointment sent me to a cardiologist who diagnosed a medication interaction (what I needed were fewer meds, not more). When I had a severe depressive episode after my father's death and the medication was ineffective, I was told to take a half hour walk per day, after I had told the doctor I was walking the dog three times per day.

The research supports that those with mental health diagnoses—particularly women — are not read as reliable narrators (Pryal, 2010), and I think I had largely internalized that. Because I had a diagnosis of depression, even if I was managing well, every time I left the doctor's office with a starter pack of Zoloft (“Just take it if you need it and I can call more in"), I wondered if I was really okay. In other words, as Kimberly Emmons (2010) described, we can view depression "as central, at the core of an individual's experience. Beliefs such as this make depression more than an illness; they make it an identity" (Emmons, 2010, p. 90). Even though my career has been stable and traditional (Ph.D., tenure track job, tenure, twenty-plus years at one university), I found myself worried about disclosure — both for myself and the more junior people writing here. Even while attempting to create a space for openness around issues of mental health diagnoses, I was conscious of audience and how an earlier career academic might be pigeonholed. I hope readers will join me in honoring the tenacity and vulnerability these dialogue participants bring to their experiences below. 
Jay: I've found Melanie Yergeau's $(2017,2013)$ work within the autism community and advocating for neuroqueer embodiments to be one of the critical factors that helped me realized my own trans identity and to continue to actively embody neurodivergence. As a white trans woman who people still read as masculine, I try to leverage my privilege in order to push neuroqueer embodiments into the view of neurotypicals and confront their own normative assumptions about the world. This often means wearing my diagnoses on my sleeve, in front of students, peers, and administrators.

Alyssa: I own and frequently wear a bright orange T-shirt with a picture of a giraffe with a lampshade on its head that reads “Autistic Party Giraffe." Reading Yergeau's (2013) "Clinically significant disturbance" and dealing with administrators who didn't want me on a study abroad program scared me off disclosing for a while, but I'm not good at subtle.

Jay: Disclosing to my students comes easy, for me, actually. Because I'm a gender nonconforming trans woman, my gender performance will often already invite harassment. In some ways, the feeling of exposure caused by my trans-ness makes me less worried about extra exposure.

Alyssa: My first three semesters teaching, I didn't tell my students. In the fourth semester, I disclosed it after making a vaccine joke that I wouldn't have wanted to hear from a non-autistic person. (Of course, I get my flu shot, wouldn't want to run out of autism!) I followed up with, “I'm autistic, I can make that joke.” In my fifth semester, I needed to teach and couldn't talk my students found out when I started answering their questions by writing on index cards, I'd leave with them instead of speaking.

\footnotetext{
${ }^{8}$ Alyssa employs Augmentative and Alternative Communication strategies (AAC) to communicate when they need them in teaching. C.F. Hillary, 2019; Hillary \& Harvey (2018); Zisk \& Dalton (2019).
} 
Emily: I am only out to students in the class I teach in Intergroup Relations. . I model narrative telling by sharing my personal story with borderline personality disorder and the systemic and structural issues that go along with living with mental illness. Sharing my story has been empowering as it gives other students permission to share their stories as well.

I've noticed that many people, including myself, attribute every mistake I make to borderline personality, and that's not always the case. I see myself pathologizing my every move and every interaction, blurring the lines between sometimes healthy and sometimes ill, and further reinforcing my "broken personality" that the DSM and so many studies perpetuate.

Lucia: Since my diagnosis is so recent, my disclosure tends to happen on a one-on-one basis with students. If I see them struggling with anything that doesn't seem "relevant" to their academic work, I will likely open up and tell them about the ways I feel hindered and my coping mechanisms to survive and thrive. In general, I've been talking openly about my need to take boxing classes and walks on a regular basis as well as make time to recharge over the weekend with the idea of letting folks know that my outward accomplishments take a lot of inward maintenance!

While the decision to be visible as neuroatypical is sometimes not a choice, difference is always a risk. As Jay points out, being visibly different can force neurotypicals to confront their own assumptions about what is normative. The daily negotiations of mundane requirements and expectations like deadlines, access to learning management platforms, and teaching times regularly leads to decisions about who to disclose to and why. For example, does IT need to know that early access to Blackboard is necessary for you to manage your learning differences? Do you want to invoke the ADA when asking for afternoon teaching times or do you just hope you have a sympathetic and flexible chair? Price eloquently describes the needs for more flexible 
attendance policies for students with mental health diagnoses, and those of us with mental health diagnoses are hopefully implementing some of Price's and Dolmages'strategies in our classrooms (alternative ways of participating in class discussions, for example). However, while we try and offer accommodations to our students, we struggle with when and how we disclose.

\section{Affordances and Struggles}

In Reynolds' (2018) overview of the current research in mental disabilities, he noted that many of the researchers have a personal connection to their subject matter, whether through colleagues or friends. While not all of us research exclusively in mental health rhetoric, all of us have touched on it in our work. We find that our neuroatypical behaviors can be misread. Asking for a later teaching time, for example, can be viewed as "lazy" rather than a reasonable accommodation for the effects of a new medication. Paradoxically, in academe, several of us have found that some of the symptoms of our mental "disabilities" are viewed as favorable characteristics. Hypomania can be seen as being "high energy" and a valuable skill because you are productive; in a Chronicle of Higher Education article, English education professor Peter Smagorinsky described his autism spectrum disorder, anxiety, and OCD as “enabling” because they gave him "hyper focus" and assisted in his productivity (Sarah Brown, 2016, para. 21). The other symptoms of our mental health diagnoses or what we need for self-care (time alone, time to work out, time for doctors and therapy appointments) or our behaviors (stimming, opting out of social events, saying no to "extras") can be seen as strange or uncollegial. Selections from our conversation below make it clear that we are adapt at finding working arounds or working through some of the challenges we encounter and that some aspects of academic life (much independent work on our own) can mask the challenges of mental health symptoms. 
Lucia: It's funny because I've been noticing that one of the things that has made me successful professionally is actually tied to anxiety. I've been able to plan and anticipate needs (which with anxiety can lead to never-ending spirals), be detail-oriented when I need to be (which takes me to worry and sweat the smaller stuff), and be very attentive to my audience (which can manifest as people pleasing).

Emily: Basically, I characterize myself as living liminally, or as he would say, "liminal entities are neither here nor there; they are betwixt and between the positions assigned and arrayed by law, custom, convention, and ceremonial” (Victor Turner, 1969, p. 369)

Patrick: Emily, I just wanted to note that I'm intrigued by the way you're framing BPD as an identity that has its own merits.

Alyssa: That concept of liminality is super interesting to me. I'm probably going to want to take a look at that. There's also neurodiversity; there's Mad Pride.

Leah: As a bipolar person, I am subject to prolonged periods of depression and hypomaniaconditions that make it difficult to focus on or complete extended projects (such as a dissertation!). My main hope for the upcoming year is to relearn my brain and find a more effective process for "thinking” work.

Patrick: Leah, I don't necessarily have a question for you, but I wanted to offer my well-wishes on your relearning project. I went through some medication changes early in my dissertation process, and it was an "interesting" time to be figuring out functions of my brain, but it can be done! :)

Rebecca: I was diagnosed with BPD and PTSD last year and ever since I have been trying to learn how to manage it. When I learned that I had to teach, I had a panic attack because my 
depression and social anxiety is something that I greatly struggle with, but as I began to teach, I learned my teaching strategies to help minimize them, and I want to learn what others have done.

Emily: Rebecca, I was immediately drawn to your description as I also have BPD. My thesis is an autoethnography of my personal experiences living with and navigating BPD in the realm of patient-provider contexts. I'm wondering if/how your BPD diagnosis has impacted your teaching/school/research? BPD manifests differently in each individual, so I'd love to hear more about your experiences.

Rebecca: I have always gotten good grades and I can finish many of the assignments. The only thing I can see was that maybe I was never good at taking criticism for my work. I shut down. My low self-esteem makes me want to just quit my field. But I am learning, and I think just reading about BPD has helped me.

Bailey: Basically, when I was teaching (in 2016 and 2017), I found that I could pull off a full class, up to my usual teaching standard (or at least close to it), even if I walked into the room in the middle of a deep depressive episode. I could ignore my reading, my writing, my other coursework, decent food, etc., but I almost always found a way to teach. It never exactly energized me, and it always exhausted me. But I found that knowing 18 to 35 students were relying on me to get in there and do what I was getting paid to do was somehow enough to quell the outward signs of depression for an hour and a half a couple times a week.

It doesn't work for me anymore, so I know it's not a response to work I'm expected to do. I think it just falls along the line of "benecrasting," aka the phenomenon of willingly procrastinating on one's own tasks to do similarly intensive ones for other people. I'm always afraid to articulate this phenomenon for fear of the response that (a) my depression is obviously 
all in my head or (b) I just need to try harder to get out of it. Both of those things are false, but my experience of briefly short-circuiting depression is true and puzzling.

Alyssa: I like the benecrasting thought. I always managed to keep up with my teaching related tasks (and still do, teaching for the Art of Problem Solving) and generally have quicker responses in keeping up with the few research projects I agree to participate in as not-the-main-researcher than I do with my own work.

\section{Advocacy and Accommodations}

As a more senior participant in this dialogue, I wondered a lot about effective accommodations. As an undergraduate, long before the 2008 revision of the ADA to include psychiatric conditions, one of my professors told me that the best students often needed more time to complete assignments. After I handed in a paper that one of my professors generously called an outline, I came to understand that I could and should ask for additional time if the exhaustion that comes with depression got to be too much. My experience has driven how I shape my requirements for students. If a student asks for an extension, she gets it. She does not need to give me a reason. Any written final exam can take any student as long as it takes, whether the accommodation is official and documented or not. But while we have begun to find ways forward for our students, academics themselves still have difficulty accessing and requesting accommodations. Stephanie Goodwin and Susanne Morgan (2012) discuss the impact of chronic illness on an academic career. They argue, "academic institutions generally have good policies for accommodating students with disabilities, but few models exist for parallel accommodation to promote the success of faculty members with disabling illnesses." 
When I recently considered asking for accommodations for depression, as a tenured faculty member, I had no idea how to proceed. While we have an office for students with disabilities, there is no clear path for a faculty member with a mental disability to obtain accommodations. When I published in The Chronicle of Higher Education (Green, 2013) about not asking for FMLA when my spouse was hospitalized, HR immediately wanted to talk with me about how I could have called them for accommodations. But asking for family medical leave or accommodations requires a certain level of trust with your institution, and it is helpful to have access to clear procedures. Also, there is still tremendous silence about accommodations, and, anecdotally at least, I have found it easier to access accommodations for caregiving. After I did manage to obtain a course release for my mother's care when she was on hospice, I was approached by other faculty to ask if "I would talk with X" about how I had gotten the accommodation. In other words, even when there is a written process (which there was in this case), tenured faculty are hesitant to access it; when there is no clear path for accommodations for a chronic or fluxuating condition, it is much more difficult to figure out a path forward.

Jay Dolmage (2017) argued that “The perspective of disability . . . shouldn’t just be included in our classroom, shouldn't just be reflected in the design of our teaching practices and technologies; it must change what we do" (p. 84). Changing what we do goes beyond the forms and procedures typically offered by an office for students with disabilities. So how do we change what we do? And, perhaps just as importantly, how do we ask for what we need? Price (2011) called for "Access ... designing spaces — including kairotic professional spaces - in ways that are flexible, multi-modal, and responsive to feedback" (p. 130). And Dolmage (2017) described using the idea of "universal design" as a verb and process, "a way to move," but what does this look like in practice (p. 188). 
The American Association of University Professors (2012) published a document on accommodating faculty with disabilities, "Accommodating faculty members who have disabilities," that offered guidance to institutions such that they might prepare robust policies in compliance with the Americans with Disabilities Act of 1972. Unfortunately, our experiences reveal that neuroatypicality is still poorly understood or even derided; accommodations, as a result are not always abundant or advantageous. In our dialogue, what became clear was that we have so far to go in embracing difference and acknowledging different modes of learning. Despite nods to "crip time," (Price, 2011, p. 62-3; Samuels, 2017) in the neoliberal university where resources, like time, are scarce and commodified, how do we throw a wrench in the mechanisms driving the corporate university? Pieces of our conversation below show that traditional accommodations fail to account for the vagaries of life with a mental disability. Likewise, the labor involved in seeking accommodations can be prohibitive and daunting. Flexibility is perhaps the most humane accommodation out there.

Ann: It's always assumed (at my place anyway) that faculty don't need accommodations for their stuff. In other words, faculty always seem to be coded as "normal" or "neurotypical." Alyssa: My sole formal accommodation is my use of augmentative and alternative communication (AAC) strategies as needed, because I'm autistic and my ability to speak is highly variable. Informally, I work remotely way more often than anyone else in my lab because of my sensory processing issues. When I sent the first version [of the accommodations letter] to a professor before meeting with her, she said she was happy to accommodate, but had no idea what it was I actually needed.

Leah: I choose not to apply for accommodations because I find the heavy focus on documentation off-putting. I also believe that the standard accommodations are not particularly 
useful to someone like me. I find a lot of the standard accommodations to be rigid or static, and they don't do much in terms of assisting me for a sustained period of time-either in the role of a student or teacher.

Jay: Despite having extensive documentation ... my current one wished to handle my needs on a "caseby-case" basis which makes it my job to interpret both programmatic employment policies and teacher policies (as I'm still a graduate student in course work). The experience of the labor and needing to "prove" disability constantly just made me give up entirely on the process. Speaking with other disabled colleagues in my department, I've gathered this to be a common experience. Bailey: I'm not sure I've mastered what it means to advocate for myself in the ways I need most. Useful accommodations are difficult to outline when you're not sure if you'll be able to get out of bed in the morning. The best I can do now is recognize that if I didn't have a semi-flexible schedule at work (just by nature of the job), I wouldn't even have a job at all.

Alyssa: While I don't think the availability of formal accommodations inherently prevents good teaching, I do think the expectation that all accommodations must be formal, or that certain kinds of accommodations must be formal, can interfere with both good teaching and with accessibility as a practice.

Lucia: Interesting, Alyssa. This speaks to my fear of making an official disclosure at the risk of being judged (wrongly), so instead, I have just opted to "pass."

Alyssa: If I need to go in and do paperwork and ask for an exception, that's a heck of a lot of extra work that has to be done every time, and since it's some sort of extra exception, people often feel entitled to not make it happen. That's not access. Access is when I can show up and have what I need, without piles of extra work the enabled folks don't need to do. 
Ann: I get it now. My Jesuit institution has a phrase "cura personalis" or care of the whole person. We try to see every person needing individual, not accommodations, but *are.* We try and acknowledge that faculty, staff, and students are all human beings in relationship with one another. Bell hooks discusses the difference between being the "exception" and "exceptional." She writes: At the root . . is the longing for reinforcement of the belief in 'the exception' which enables race, sex, and class biases to remain intact. I am careful to separate what it means to be exceptional

from a notion of "the exception" (1989, p. 82). We can create spaces where everyone is exceptional rather than reinforcing the notion of accommodations being "the exceptions." Emily: I have been fortunate enough to have understanding and accommodating professors who make an effort to have a continued dialogue throughout the semester regarding my needs and ability to be successful in their courses.

Alyssa: I have a lot of complicated feelings about the accommodations talk. As a teacher, I know I'm not supposed to ask more about people's disabilities (and I don't), but I have asked students coming in with letters if there's anything not on the letter that I could do to help them. As a student, I tell people exactly what's up: I'm autistic, sometimes I can talk and sometimes I can't, here's a pile of backup communication options.

Jay: I try as much as possible to make space for my students' disabilities and never question whether their disclosure and needs are anything but the truth. Finally, I thank them for sharing and trusting me.

Lucia: I try to use this as an opportunity for hospitality. Students are generally surprised at my acceptance and creativity in looking for ways to make things work for them. I suspect that for some of them it has been the first time. 


\section{Closing Thoughts and Notes on Process}

Having participated in a previous RHM dialogue (Molloy et. al. 2018), where we, due to time constrains, answered a series of asynchronous questions that were then edited, I wondered if I could create space for more community-building in an online collaboration. I wondered if I could provide space for building longer term relationships as well as space for highlighting a diversity of voices. In addition, I reflected on alternative forms of scholarship. bell hooks' selfinterviews and interviews came to mind, as did Blitz and Hurlbert's (1991) and their use of transcriptions from face-to-face meetings at the Conference on College Composition and Communication, ${ }^{9}$ but we were restricted by time and space and my own limits with technology.

What is also relatively clear is that we, as a field, have a long way to go in restructuring the academy to accommodate mental health diagnoses for faculty, students, and staff. Putting this dialogue in the larger context of working conditions for faculty, with $70 \%$ of faculty currently contingent and with the largest area of growth in the profession being the full-time, non-tenure track appointments, academia seems to be determined to create more flexible employment conditions for employers without viewing continuing, tenured, faculty as the university's most valuable resource. Fighting for cultural shifts in such a hostile context seems particularly naïve, and the desire to hunker down and work out the best individual solution is enticing, but it is not sustainable. I believe it is through collective dialogues and collective action that we can transform our working conditions. I was heartened to learn of recent anti-racist work from the California Faculty Association, and I wonder what collective action from some of our largest professional organizations could do. At the most recent Conference on College Composition and

\footnotetext{
${ }^{9}$ Blitz and Hurlbert had face-to-face conversations at the Conference on Composition and Communication.
} 
Communication (2019), a poster that declared the Convention "accessible" was quickly decorated with post-it notes pointing out the flaws in that statement. Clearly, we have a long way to go in applying disability studies activism to the material conditions of faculty work and lives. And we do not know what voices we are missing as there is increasing pressure to "do more with less" in the apocryphal narrative of the downfall of higher ed. ${ }^{10}$ What gives me hope and continues to challenge me are the voices of the next generation of scholars who are using their energy and engagement to work for change, and you can hear some strong and compelling examples in this dialogue. It has been a privilege to think about how voices like these can not only add to the current discourse, but also how it might transform it.

\section{Author Bios}

Alyssa (they/them/theirs): Alyssa is a white, Autistic, nonbinary, Jewish doctoral candidate in interdisciplinary neuroscience at the University of Rhode Island. They research many things, including augmentative and alternative communication (AAC), brain-computer interfaces (BCIs), and neurodivergent representation, and they teach chemistry and math.

Rebecca Carrasco is a Rhetoric and Writing Studies master's student at the University of Texas at El Paso. Her thesis entitled Strategies of Outliers/Positive Deviants who are Successful Teachers Despite their Mental Illness brings to light the tools teachers created to teach despite having a mental illness.

\footnotetext{
${ }^{10}$ I do not doubt that academia as we know it is lost or that many colleges will go out of business in the next decade. What I do dispute is the overwhelming narrative that tenure stream faculty are the cause.
} 
Lucía Durá is Associate Professor of Rhetoric and Writing Studies in the English Department and Associate Dean of the Graduate School at The University of Texas at El Paso. Her work on positive deviance, intercultural communication, and participatory methodologies focuses on leveraging the assets of vulnerable populations to solve complex problems.

Ann E. Green is a professor of English at Saint Joseph's University. She teaches servicelearning, and also teaches in the Inside/Out program, a course held in a prison where the students are both incarcerated and traditional. She has previously published in Academe, College Composition and Communication, and RHM.

Patrick Harris teaches English at the University of Nevada, Reno. His research focuses on decensoring neurodiversity, especially within the academy.

Leah Heilig is a PhD candidate of Technical Communication and Rhetoric at Texas Tech University. Her work has appeared in Technical Communication Quarterly, Business and Professional Communication Quarterly, and Communication Design Quarterly. Her research investigates questions of access, equity, and advocacy in the design of communication.

Bailey Kirby is the grants administrator in the computational science and engineering research center (SimCenter) at the University of Tennessee at Chattanooga. She is an online PhD student in Technical Communication and Rhetoric at Texas Tech University, where she 
also completed her M.A.

Jay McClintick (she/her \& they/them) is a genderqueer neuroqueer trans woman getting her PhD in Rhetoric at the University of Arizona. She is considered a resident troublemaker and is okay with this.

Emily Pfender is an adjunct instructor at Harrisburg Area Community College where she teaches communications. She also works in the field of Applied Behavior Analysis as a Registered Behavior Technician. She completed her M.A. at Villanova University and is a Ph.D. student in communication at the University of Delaware.

\section{Acknowledgements:}

Thank you to the editors of RHM for their guidance and patience as this article evolved, and thanks to the insightful comments from the anonymous reviewers whose constructive and supportive suggestions shaped the final version. Particular thanks to reviewer \#2 for identifying the bell hook quote used from Talking Back (1989). In addition, thanks to Susan Naomi Bernstein who provided particular editorial assistance during the final editing stage. 


\section{References}

Abraham, Amelia (2016, November 18). Remembering Mad Pride, The Movement That Celebrated Mental Illness. Retrieved from https://www.vice.com/en_uk/article/7bxqxa/mad-pride-remembering-the-uks-mentalhealth-pride-movement

Accommodating Faculty Members Who Have Disabilities. (n.d.). Retrieved from https://www.aaup.org/sites/default/files/disabilities.pdf

Blitz, Michael and Hulbert, Mark (1991) Composition and Resistance. Portsmouth, NH: Boyton/Cook.

Brown, Sarah. (2016, September 18). How 4 Professors Built Careers Despite Mental-Health Struggles. Retrieved March 1, 2020, from https://www.chronicle.com/article/How-4Professors-Built-Careers/237791

Davi, A., Dunlap, Michelle , \& Green, Ann E. (2008) Feminist ways of seeing: Preparing students for service learning. In Karen Dugger (Ed.), Handbook on Service-Learning in Women's Studies, Interdisciplinary Studies, and the Disciplines. The Institute for Teaching and Research on Women, 14-25; 91-92.

Dolmage, Jay Timothy (2017). Academic ableism: Disability and higher education. University of Michigan Press.

Emmons, Kimberly K. (2010). Black dogs and blue words: Depression and gender in the age of self-care. Rutgers, NJ: Rutgers UP.

Glaser, Gabrielle. (2008, May 11). 'Mad Pride' Fights a Stigma. Retrieved from https://www.nytimes.com/2008/05/11/fashion/11madpride.html 
Green, Ann E. (2003). Difficult stories: Service-learning, race, class, and whiteness." College Composition and Communication, 276-301.

Green, Ann E. (2003). Learning to tell stories: Pedagogy, "the personal” and social class." Modern Language Studies, 80-89.

Green, Ann E. (2018, October). Creating community, inside/out. Blog. Macmillan Community. Retrieved from https://community.macmillan.com/community/the-englishcommunity/bedford-bits/blog/2018/10/22/creating-community-insideout

Hillary, Alyssa. (2019). Am I the curriculum? Curriculum Inquiry, 49(4), 373-386.

Hillary, Alyssa, \& Harvey, Sam. (2018). Teaching with augmentative and alternative communication. In Michael S Jeffress (Ed.), International Perspectives on Teaching with Disability: Overcoming Obstacles and Enriching Lives.

hooks, bell. (1989) Talking back: Thinking feminist, thinking black. Boston, MA: South End Press.

. (1994) Teaching to transgress. New York: Routledge.

Holladay, Drew. (2017). Classified conversations: Psychiatry and tactical technical communication in online spaces.” Technical Communication Quarterly 26 (1), pp. 8-24. Lewiecki-Wilson, Cynthia (2003). Rethinking rhetoric through mental disabilities. Rhetoric Review. 22 (2), 156-67.

Molloy, Cathryn, Beemer, Cristy, Bennett, Jeffrey, Green, Ann, Johnson, Jenell, Kessler, Molly, Novotny, Maria \& Siegel-Finer, Bryna (2018). A dialogue on possibilities for embodied methodologies in the rhetoric of health \& medicine. Rhetoric of Health \& Medicine, 1(34), 349-371. 
Molloy, Cathryn. (2015). Recuperative ethos and agile epistemologies: Toward a vernacular engagement with mental illness ontologies.

Goodwin, Stephanie A., \& Morgan, Susanne (2012). Chronic illness and the academic career. Retrieved from https://www.aaup.org/article/chronic-illness-and-academic-career Pettit, Emma. (2016, August 4). Stigma, Stress, and Fear: Faculty Mental-Health Services Fall Short. Retrieved from https://www.chronicle.com/article/Stigma-StressFear/237353?key=88BE4S66owvEMmZ0_1Sfd13azf_zCHpO5Nr0NB0IylIbsEiYysGPUJu7UmemNI5eDFHM1FuRIM0UXoxMmJCZ1NzekhvUGlsamFVS0NGN2IxbXhuQ mJXNGJiMA

Prendergast, Catherine (2001). On the rhetorics of mental disability. Embodied Rhetorics: Disability in Language and Culture. Cabondale: Southern Illinois UP

Price, Margaret (2011). Mad at school: Rhetorics of mental disability and academic life. Ann Arbor: University of Michigan Press.

Pyral, Katie Rose Guest. (2010). The genre of the mood memoir and the "ethos" of psychiatric disability. Rhetoric Society Quarterly, 40(5), 479-501.

Ratcliffe, Krista (2005). Rhetorical listening: identification, gender, whiteness. Carbondale: Southern Illinois University Press.

Reynolds, J. Fred. (2018). A short history of mental health rhetoric research (MHRR). Rhetoric of Health \& Medicine, 1(1-2), 1-18.

Richardson, Hannah. (2019, May 23). University counselling services 'inundated by stressed academics'. Retrieved from https://www.bbc.com/news/education-48353331

Samuels, Ellen. (2017). Six ways of looking at crip time. Disabilities Studies Quarterly. 37.3. https://dsq-sds.org/article/view/5824/4684 
Turner, Victor. (1969). The ritual process: Structure and anti-structure. New Brunswick, NJ: AldineTransaction.

Yergeau, Melanie. (2013). Clinically significant disturbance: On theorists who theorize theory of mind. Disability Studies Quarterly, 33(4).

Yergeau, Melanie. (2017). Authoring autism: On rhetoric and neurological queerness. Durham, NC: Duke University Press.

Zisk, Alyssa Hillary \& Dalton, Elizabeth. (2019). Augmentative and alternative communication for speaking autistic adults: Overview and recommendations. Autism in Adulthood, 1(2). 